\title{
Substratos e temperaturas para germinação e vigor de sementes de tomateiro
}

Josiane Cantuária Figueiredo, Andréia Márcia Santos de Souza David, Cleisson Dener da Silva, Lucas Vinícius de Souza Cangussu, Dayana Lúcia Mota Pinheiro Bernardinho, Rebeca Alves Nunes da Silva, Larissa Medeiros Soares

Universidade Federal de Pelotas - UFPEL, RS. E-mail: josycantuaria@yahoo.com.br

\section{Resumo}

O estabelecimento das condições ideais para a germinação, principalmente da temperatura e do substrato, é de extrema importância, tendo em vista que estes fatores variam entre sementes de diferentes espécies. Assim, o objetivo do presente trabalho foi definir substratos e temperaturas para germinação de sementes de tomateiro, cultivar IPA 6. O trabalho foi conduzido no Laboratório de Análise de Sementes, do Departamento de Ciências Agrárias (DCA) da Universidade Estadual de Montes Claros (UNIMONTES). O delineamento experimental utilizado foi o inteiramente casualizado, com os tratamentos distribuídos em esquema fatorial $2 \times 5$, sendo duas temperaturas (constante de 25 e alternada de 20-30 ${ }^{\circ} \mathrm{C}$ ) e cinco substratos: areia, areia + esterco bovino (1:1), areia + Bioplant ${ }^{\circledR}$ (1:1), areia + composto orgânico (1:1), e areia + vermiculita (1:1), com quatro repetições de 50 sementes por tratamento. Os parâmetros avaliados foram: germinação, primeira contagem da germinação, índice de velocidade de germinação, comprimento de plântulas, massa da matéria fresca e seca de plântulas. Conclui-se que a temperatura de $25{ }^{\circ} \mathrm{C}$ e os substratos areia, areia + Bioplant ${ }^{\circledR}$ e areia + vermiculita são condições ideais para a germinação e vigor das sementes de tomaterio.

Palavras-chave: areia; composto orgânico; Solanum lycopersicum.

\section{Substrates and temperatures for germination and vigor of tomato seeds}

\begin{abstract}
The establishment of the ideal conditions for germination, especially temperature and substrate, is of extreme importance, considering that these factors vary between seeds of different species. Thus, the objective of the present work was to define substrates and temperatures for germination of tomato seeds, IPA 6 cultivar. The work was conducted at the Laboratory of Seed Analysis, Department of Agrarian Sciences (DCA) of the State University of Montes Claros (UNIMONTES). The experimental design was a completely randomized design, with the treatments distributed in a $2 \times 5$ factorial scheme, two temperatures $\left(25\right.$ and alternating between $20-30^{\circ} \mathrm{C}$ ) and five substrates: sand, sand + bovine manure (1: 1 ), sand + Bioplant ${ }^{\circledast}(1: 1)$, sand + organic compost (1:1), and sand + vermiculite (1:1) with four replicates of 50 seeds per treatment. The evaluated parameters were: germination, first germination count, germination speed index, seedling length, fresh and dry matter mass of seedlings. It was concluded that the temperature of $25^{\circ} \mathrm{C}$ and the substrates sand, sand + Bioplant ${ }^{\oplus}$ and sand + vermiculite are ideal conditions for germination and vigor of tomato seeds.
\end{abstract}

Keywords: sand; organic compost; Solanum lycopersicum.

\section{Introdução}

Entre as hortaliças mais consumidas encontrase o tomate, que possui excelentes compostos para a saúde humana, como vitamina $C$ e licopeno (YA-DAN et al., 2017). É uma cultura de ciclo relativamente curto, de altos rendimentos e com boas perspectivas econômicas (FERREIRA, 2004). Estando relacionado à agricultura familiar, apresenta uma grande importância 
socioeconômica, contribuindo para a geração de emprego e renda para o produtor.

Vários fatores afetam a produção do tomateiro, desde a germinação das sementes até o seu desenvolvimento. Nesse sentido, a germinação é fase crucial no estabelecimento e desenvolvimento das plântulas, existindo diversos fatores que influenciam neste processo (SOUZA et al., 2012).

A temperatura e o substrato são dois fatores importantes que exercem acentuada influência no comportamento germinativo das sementes. 0 conhecimento das condições ideais para a germinação é de fundamental importância, principalmente, pelas respostas diferenciadas que elas podem apresentar em função de diversos fatores, como viabilidade, condições de ambiente, envolvendo água, luz, temperatura, oxigênio, associados ao tipo de substrato para sua germinação (BRASIL, 2009; CARVALHO; NAKAGAWA, 2010).

A temperatura considerada ótima é aquela na qual a semente expressa seu potencial máximo de germinação e as temperaturas máximas e mínimas caracterizam pontos críticos onde acima e abaixo das quais, respectivamente, não ocorre germinação (SOUZA et al., 2012). Nesta perspectiva, há espécies nas quais a germinação das sementes é favorecida por temperatura constante (PACHECO et al., 2010), por alternância de temperaturas, à semelhança do que acontece em condições naturais (LIMA et al., 2011), ou por faixas de temperaturas amplas (GONZÁLEZ-RIVAS et al., 2009).

Assim como a temperatura, o substrato utilizado também desempenha grande influência, no processo germinativo das sementes uma vez que fatores como estrutura, aeração, capacidade de retenção de água e grau de infestação de patógenos, entre outros, podem favorecer ou prejudicar a germinação (OLIVEIRA et al., 2012). Segundo Brasil (2009), os substratos mais utilizados são papel (toalha, filtro, mata-borrão), areia e solo. O papel é usado apenas em ensaios de germinação, sob condições controladas, não na produção de mudas. Porém é possível encontrar substratos alternativos como bagaço de cana, esterco de curral, Bioplant e vermiculita que vem sendo utilizados, devido apresentar bons resultados na produção de mudas, pois são substratos leves de fácil manuseio e boa capacidade de absorção de água. Assim, a formulação dos substratos deve atender às necessidades da planta a ser cultivada de forma que possua os teores de nutrientes necessários.

Diante do exposto, objetivou-se no presente trabalho avaliar o parâmetros de germinação e vigor de sementes de tomateiro em diferentes temperaturas e substratos.

\section{Material e Métodos}

O experimento foi conduzido no Laboratório de Análise de Sementes, do Departamento de Ciências Agrárias (DCA) da Universidade Estadual de Montes Claros - UNIMONTES, Janaúba, MG. Foram utilizadas sementes comerciais $190 \%$ de germinação) de tomateiro, cultivar IPA 6 indicada para industrialização.

$O$ delineamento experimental utilizado foi o inteiramente casualizado com os tratamentos distribuídos em esquema fatorial $2 \times 5$, sendo duas temperaturas (25 e $20-30{ }^{\circ} \mathrm{C}$ ) e cinco substratos: areia, esterilizada em estufa na temperatura de $200{ }^{\circ} \mathrm{C}$ por 2 horas, areia + esterco bovino (1:1), areia + Bioplant ${ }^{\circledast}$ (1:1), areia + composto orgânico (1:1) e areia + vermiculita (1:1). O composto orgânico foi obtido da mistura de resíduos de tomate e cana-de-açúcar. A areia, o esterco e o composto foram peneirados em peneira com malha de $5 \mathrm{~mm}$, e misturados nas proporções determinadas e homogeneizados manualmente.

Para o teste de germinação, foram utilizadas quatro repetições de 50 sementes, semeadas a uma profundidade de $1,0 \mathrm{~cm}$, em caixas de plástico do tipo gerbox $(11,0 \times 11,0 \times 3,5 \mathrm{~cm})$, preenchidas com $2 / 3$ da capacidade do seu volume, com os respectivos substratos umedecidos com a quantidade de água equivalente a $60 \%$ da capacidade de retenção de acordo com as recomendações das regras para análise de sementes (RAS) (BRASIL, 2009). As caixas foram mantidas em germinadores, previamente regulados às temperaturas de 20-30 ${ }^{\circ} \mathrm{C}$ alternada e $25{ }^{\circ} \mathrm{C}$ constante. As avaliações da germinação foram realizadas no quarto e décimo quarto dias após a semeadura com a contagem do número de plântulas normais germinadas. Consideram-se como normais as plântulas que apresentavam todas as estruturas essenciais que permitisse uma avaliação correta das mesmas e apresentavam capacidade de continuar o seu desenvolvimento e dar origem a uma planta normal.

A primeira contagem de germinação consistiu do registro da porcentagem de plântulas normais obtidas no quarto dia após o início do teste de 
germinação, e os resultados foram expressos em percentagem de plântulas normais, segundo os critérios estabelecidos pelas RAS (BRASIL, 2009).

$O$ índice de velocidade de germinação foi calculado pelo somatório do número de sementes germinadas a cada dia, dividido pelo número de dias decorridos entre a semeadura e a germinação, de acordo com a fórmula de Maguire (1962).

IVG $=(\mathrm{G} 1 / \mathrm{N} 1)+(\mathrm{G} 2 / \mathrm{N} 2)+(\mathrm{G} 3 / \mathrm{N} 3)+\ldots+$ $(\mathrm{Gn} / \mathrm{Nn})$, em que:

IVG = índice de velocidade de germinação,

$\mathrm{G} 1, \mathrm{G} 2, \mathrm{G} 3, . . ., \mathrm{G}$ = número de plântulas

computadas na primeira, segunda, terceira e última contagem;

$\mathrm{N} 1, \mathrm{~N} 2, \mathrm{~N} 3, \ldots, \mathrm{Nn}=$ número de dias da semeadura à primeira, segunda, terceira e última contagem.

No final do teste de germinação foi determinado, com o auxílio de uma régua graduada, o comprimento das plântulas (inserção dos cotilédones até a raiz) consideradas normais, de cada repetição, sendo os resultados expressos em $\mathrm{cm}$.plântula ${ }^{-1}$. Para a obtenção da matéria fresca, as plântulas normais de cada repetição foram pesadas em balança de precisão $0,0001 \mathrm{~g}$, e os resultados expressos em mg.plântula ${ }^{-1}$. Em seguida, as plântulas obtidas foram colocadas dentro de sacos de papel e secas em estufa, com circulação forçada de ar, a $65{ }^{\circ} \mathrm{C}$ constante durante 72 horas para a determinação da matéria seca. Após este período, as amostras foram colocadas para resfriar no dissecador e novamente pesadas em balança de precisão, e os resultados expressos em mg. plântula ${ }^{-1}$.

Os dados foram testados quanto à normalidade e homogeneidade, em seguida foram submetidos à análise de variância. Quando significativos os efeitos dos substratos foram estudados pelo teste de Tukey a $5 \%$ de significância. Para verificar o comportamento das variáveis, em função das temperaturas, para cada substrato o teste $F$ foi conclusivo $(p<0,05)$. Foi utilizado o programa estatístico SISVAR versão 4.0 (FERREIRA, 2011).

\section{Resultados e Discussão}

Os resultados da análise de variância revelaram efeito significativo da interação entre os fatores temperaturas $(T)$ e substratos $(S)$ para as variáveis germinação, índice de velocidade de germinação, comprimento, massa da matéria fresca e seca de plântulas, revelando a ocorrência de dependência entre os fatores estudados. Houve efeito isolado de substrato para a primeira contagem da germinação.

$\mathrm{Na}$ tabela 1 observa-se que a temperatura de $25{ }^{\circ} \mathrm{C}$ proporcionou as maiores percentagens de germinação das sementes, quando utilizou-se os substratos areia e areia + Bioplant ${ }^{\circledR}$. Para os demais substratos, as temperaturas estudadas não exerceram influência na germinação das sementes.

Tabela 1. Germinação (GER \%) e índice de velocidade de germinação (IVG) de sementes de tomateiro cultivar IPA 6, submetidas a diferentes temperaturas e substratos.

\begin{tabular}{|c|c|c|c|c|c|}
\hline \multirow[b]{2}{*}{$\begin{array}{c}\text { Temperaturas } \\
\left({ }^{\circ} \mathrm{C}\right)\end{array}$} & \multicolumn{5}{|c|}{ Substratos } \\
\hline & Areia & $\begin{array}{c}\text { Areia + esterco } \\
\text { bovino }(1: 1)\end{array}$ & $\begin{array}{c}\text { Areia }+ \\
\text { Bioplant }(1: 1)\end{array}$ & $\begin{array}{c}\text { Areia }+ \\
\text { composto } \\
\text { orgânico }(1: 1)\end{array}$ & $\begin{array}{c}\text { Areia }+ \\
\text { vermiculita } \\
(1: 1)\end{array}$ \\
\hline \multicolumn{6}{|c|}{ GER (\%) } \\
\hline 25 & $91 \mathrm{Aa}$ & $37 \mathrm{Ac}$ & $92 \mathrm{Aa}$ & $49 A b$ & $91 \mathrm{Aa}$ \\
\hline $20-30$ & $81 \mathrm{Ba}$ & $33 A b$ & $77 \mathrm{Ba}$ & $39 A b$ & $87 \mathrm{Aa}$ \\
\hline \multicolumn{6}{|l|}{$\mathrm{CV}(\%) \quad 9,5$} \\
\hline \multicolumn{6}{|c|}{ IVG } \\
\hline 25 & $10,6 \mathrm{Aa}$ & $2,1 \mathrm{Ac}$ & $9,9 \mathrm{Aa}$ & $2,4 \mathrm{Ab}$ & 10,7 Aa \\
\hline $20-30$ & $8,2 \mathrm{Ba}$ & $1,8 \mathrm{Ab}$ & 7,7 Ba & $1,5 \mathrm{Ab}$ & $8,7 \mathrm{Ba}$ \\
\hline
\end{tabular}

$\mathrm{CV}(\%) 7,9$

Médias seguidas por diferentes letras diferem significativamente pelo teste $\mathrm{F}$ (temperaturas) ou pelo teste de Tukey (substratos), a $5 \%$ de probabilidade. Letras maiúsculas comparam temperaturas, enquanto minúsculas comparam substratos. 
A eficiência da temperatura de $25{ }^{\circ} \mathrm{C}$ na germinação das sementes, provavelmente, está relacionada ao fato de ser uma temperatura adequada para a germinação da maioria das espécies tropicais e subtropicais (MARCOS FILHO, 2015). Já o bom desempenho das sementes nos substratos areia, areia + Bioplant $^{\circledR}$ e areia + vermiculita ocorreu provavelmente, devido à manutenção de umidade no substrato, proporcionando condições mais favoráveis à germinação das sementes. Considerando o efeito de substratos dentro de cada temperatura, observa-se que as maiores percentagens de germinação das sementes foram observadas nos substratos areia, areia + Bioplant $^{\circledR}$ e areia + vermiculita independente da temperatura estudada (Tabela 1). Esses resultados podem ser atribuídos a maior capacidade de retenção de água dos substratos, que disponibilizam uma maior umidade, observada visualmente, de forma a uniformizar todo o processo germinativo resultante (ALVES et al., 2011). Normalmente, a adição de matéria orgânica eleva a capacidade de retenção de água dos substratos. Provavelmente, as características de porosidade nas diferentes partes do substrato tenham exercido efeitos deletérios sobre a aeração e absorção de água quando se utilizaram os tratamentos areia + esterco bovino e areia + composto orgânico. Além disso, é preciso tomar cuidado com o excesso de água, que também é prejudicial durante a germinação.

Alguns substratos podem atuar como barreira física à germinação das sementes, prejudicando a emergência das plântulas (ARAGÃO et al., 2011).

Cabe salientar que durante a execução do teste de germinação, observou-se ressecamento superficial nos substratos areia + esterco bovino e areia + composto orgânico durante o intervalo entre as regas. Esse ressecamento pode ter causado indisponibilidade temporária de água para as sementes, o que poderia explicar os resultados inferiores obtidos nesses substratos (LONE, 2010). Além do ressecamento mencionado, é possível que os resultados desfavoráveis obtidos com estas duas misturas de substratos tenham ocorrido devido a outros fatores, como menor aeração e/ou presença de microorganismos patogênicos.

Os resultados obtidos no presente trabalho discordam dos encontrados por Medeiros et al. (2008) os quais verificaram melhores resultados na germinação de sementes de alface quando semeadas em substratos produzidos de compostos orgânicos.

Segundo Alves et al. (2015) um dos objetivos do teste de germinação é permitir que as sementes expressem o máximo potencial fisiológico. Ainda em suas considerações, esses mesmos autores ressaltam que a escolha do substrato e da temperatura é muito importante para obtenção de melhores resultados em um teste de germinação, em vista, sobretudo, da grande variação que existe entre as espécies com relação às condições mais adequadas.

Os maiores valores do índice de velocidade de germinação (IVG) foram obtidos na temperatura de $25{ }^{\circ} \mathrm{C}$ associados aos substratos areia, areia + Bioplant $^{\circledR}$ e areia + vermiculita (Tabela 1 ). Maiores valores do índice de velocidade de germinação indicam que as sementes germinaram mais rapidamente e de forma homogênea, sendo, portanto, mais vigorosas. Os substratos areia + composto orgânico e areia + esterco bovino influenciaram negativamente a velocidade de germinação. $O$ que não houve foi efeito significativo da temperatura para estes substratos.

De acordo com Carvalho e Nakagawa (2010), a temperatura na qual ocorre o maior índice de velocidade de geminação é chamada de temperatura ótima, sendo recomendada para condução do teste de germinação da referida espécie.

A interação entre temperatura e substrato foi descrita por Figliola et al. (1993), relatando que a capacidade de retenção de água e a quantidade de luz que o substrato permite chegar à semente podem ser responsáveis por diferentes respostas das sementes na mesma temperatura, como ocorreu com as sementes de tomateiro neste experimento.

Os substratos possuem diferentes níveis de disponibilidade de água de acordo com suas características físicas e provavelmente, os substratos que proporcionaram maiores valores de IVG possuem melhor estrutura, maior aeração e consequentemente melhor drenagem da água, o que pode ter favorecido a maior velocidade de germinação (FIGLIOLA et al., 1993).

Os substratos atuaram de forma independente no vigor das sementes avaliado pela primeira contagem da germinação (Tabela 2). A primeira contagem de germinação é um teste de vigor simples, realizado simultaneamente ao teste de germinação, e 
baseia-se no pressuposto de que as sementes mais vigorosas germinam mais rápido (ABUD et al., 2013).

Tabela 2. Primeira contagem da germinação (PCG) de sementes de tomate, cultivar IPA 6, submetidas a diferentes substratos.

\begin{tabular}{|c|c|c|c|c|}
\hline \multicolumn{5}{|c|}{ Substratos } \\
\hline Areia & $\begin{array}{c}\text { Areia + Esterco } \\
\text { bovino } \\
(1: 1)\end{array}$ & $\begin{array}{c}\text { Areia + } \\
\text { Bioplant } \\
(1: 1)\end{array}$ & $\begin{array}{c}\text { Areia + } \\
\text { Composto } \\
\text { orgânico }(1: 1)\end{array}$ & $\begin{array}{c}\text { Areia }+ \\
\text { Vermiculita } \\
(1: 1)\end{array}$ \\
\hline \multicolumn{5}{|c|}{ PCG (\%) } \\
\hline $80 a$ & $4 \mathrm{c}$ & $75 \mathrm{~b}$ & $2 c$ & $84 \mathrm{a}$ \\
\hline \multicolumn{5}{|c|}{$\begin{array}{ll}\text { CV (\%) } & 9,5\end{array}$} \\
\hline
\end{tabular}

Médias seguidas de mesma letra na linha, não diferem entre si pelo teste de Tukey a 5\% de probabilidade.

Verificou-se maior germinação na primeira contagem quando se utilizou os substratos areia e areia + vermiculita, revelando-se ideais para a germinação dessas sementes (Tabela 2). A adição de vermiculita nos substratos é altamente benéfica, pois esse mineral micáceo absorve até cinco vezes o próprio volume em água (FILGUEIRA, 2013).

Já nos substratos areia + esterco bovino e areia + composto orgânico, a germinação foi afetada por ocasião da primeira contagem da germinação, pois observou-se valores pouco expressivos. Sabe-se que o aproveitamento de resíduos orgânicos na composição de substratos para a germinação das sementes contribui sensivelmente com a aeração, capacidade de retenção de água e consequentemente com o desenvolvimento adequado das plantas (SANTOS et al., 2010). Isso explica, em parte, a menor percentagem de germinação na primeira contagem nos substratos compostos por resíduos orgânicos. Provavelmente esse material orgânico não ofereceu uma aeração adequada interferindo de forma prejudicial na germinação das sementes de tomate.

Resultados satisfatórios no índice de velocidade de germinação e na primeira contagem da germinação (Tabelas 1 e 2) são importantes uma vez que avaliam o vigor das sementes, fornecendo informações adicionais sobre o desempenho, potencial germinativo, velocidade e uniformidade no crescimento das plântulas.

Os substratos areia e a mistura de areia + Bioplant ${ }^{\circledR}$ propiciaram os maiores comprimentos de plântulas na temperatura de $25{ }^{\circ} \mathrm{C}$ (Tabela 3). Possivelmente, esses substratos tenham proporcionado maior aeração e capacidade de retenção de água, o que aliado a uma degradação mais eficiente das reservas presentes nas sementes, tenha favorecido o desenvolvimento das plântulas, uma vez que nessa fase todo o desenvolvimento das plântulas se deve à composição química das sementes (GUEDES et al., 2010). 
Tabela 3. Comprimento (CP), massa da matéria fresca (MF) e seca (MS) de plântulas oriundas de sementes de tomate, cultivar IPA 6, submetidas a diferentes temperaturas e substratos.

\begin{tabular}{|c|c|c|c|c|c|}
\hline \multirow[b]{2}{*}{$\begin{array}{c}\text { Temperaturas } \\
\left({ }^{\circ} \mathrm{C}\right)\end{array}$} & \multicolumn{5}{|c|}{ Substratos } \\
\hline & Areia & $\begin{array}{c}\text { Areia + esterco } \\
\text { bovino }(1: 1)\end{array}$ & $\begin{array}{c}\text { Areia }+^{+} \\
\text {Bioplant }^{\bullet}(1: 1)\end{array}$ & $\begin{array}{c}\text { Areia }+ \\
\text { composto } \\
\text { orgânico }(1: 1) \\
\end{array}$ & $\begin{array}{c}\text { Areia }+ \\
\text { vermiculita } \\
(1: 1) \\
\end{array}$ \\
\hline \multicolumn{6}{|c|}{ CP (cm.plântula ${ }^{-1}$ ) } \\
\hline 25 & $10,44 \mathrm{Bab}$ & $8,71 \mathrm{Abc}$ & $11,21 \mathrm{Ba}$ & $7,55 \mathrm{Ac}$ & $8,86 \mathrm{Bbc}$ \\
\hline $20-30$ & $14,77 \mathrm{Aa}$ & $7,85 \mathrm{Ab}$ & $13,97 \mathrm{Aa}$ & $5,95 \mathrm{Bb}$ & $15,32 \mathrm{Aa}$ \\
\hline \multicolumn{6}{|l|}{ CV (\%) 5,87} \\
\hline \multicolumn{6}{|c|}{ MF (mg.plântula ${ }^{-1}$ ) } \\
\hline 25 & $0,75 \mathrm{Aa}$ & $0,32 \mathrm{Ab}$ & $0,79 \mathrm{Ba}$ & $0,70 \mathrm{Aa}$ & $0,32 \mathrm{Bb}$ \\
\hline $20-30$ & $0,72 A b$ & $0,25 \mathrm{Ac}$ & $1,25 \mathrm{Aa}$ & $0,19 \mathrm{Bc}$ & $1,23 \mathrm{Aa}$ \\
\hline \multicolumn{6}{|l|}{$C V(\%) 6,56$} \\
\hline \multicolumn{6}{|c|}{ MS (mg.plântula ${ }^{-1}$ ) } \\
\hline 25 & $0,23 \mathrm{Aa}$ & $0,04 \mathrm{Bb}$ & $0,24 \mathrm{Aa}$ & $0,18 \mathrm{Aa}$ & $0,08 \mathrm{Bb}$ \\
\hline $20-30$ & $0,23 \mathrm{Aa}$ & $0,10 \mathrm{Ab}$ & $0,21 \mathrm{Aa}$ & $0,02 \mathrm{Bb}$ & $0,19 \mathrm{Aa}$ \\
\hline
\end{tabular}

Médias seguidas por diferentes letras diferem significativamente pelo teste $\mathrm{F}$ (temperaturas) ou pelo teste de Tukey (substratos), a $5 \%$ de probabilidade. Letras maiúsculas comparam temperaturas, enquanto minúsculas comparam substratos.

Na temperatura alternada de $20-30{ }^{\circ} \mathrm{C}$, os maiores comprimentos de plântulas foram observados nos substratos areia, areia + Bioplant $^{\circledR}$ e areia + vermiculita (Tabela 3). Provavelmente, essas combinações de temperatura e substratos ofereceram condições adequadas para as plântulas expressarem o seu máximo desenvolvimento. Biasi et al. (1995) trabalhando com diferentes substratos na germinação de sementes de tomate, verificaram que os maiores comprimentos de plântulas foram provenientes de sementes submetidas à temperatura de $25^{\circ} \mathrm{C}$ com o substrato bagaço de cana. Os resultados do presente trabalho em associação com os encontrados por Biasi et al. (1995), justificam a necessidade de estudos que busquem a melhor temperatura e substrato para a germinação de sementes da espécie.

Para a massa fresca de plântulas, nota-se que as maiores médias foram obtidas quando se utilizou a temperatura alternada de $20-30{ }^{\circ} \mathrm{C}$ e os substratos areia + Bioplant ${ }^{\circledR}$, areia + vermiculita, enquanto na temperatura constante $\left(25^{\circ} \mathrm{C}\right) \mathrm{O}$ substrato areia + composto orgânico não diferiu da areia pura e da mistura areia + Bioplant ${ }^{\circ}$ (Tabela 3).

Para a massa seca de plântulas (Tabela 3), na temperatura alternada de $20-30{ }^{\circ} \mathrm{C}$ os maiores valores foram obtidos nos substratos areia, areia + Bioplant ${ }^{\circledast}$ e areia + vermiculita, enquanto na temperatura de $25^{\circ} \mathrm{C}$, os substratos areia, areia + Bioplant ${ }^{\circledR}$ e areia + composto orgânico proporcionaram os maiores resultados.

A determinação da massa seca é uma maneira de avaliar o crescimento das plântulas, em que se consegue determinar, com precisão, a transferência de reservas da semente para o eixo embrionário, de forma que as amostras com maior massa seca são consideradas de maior vigor (NAKAGAWA, 1999).

\section{Conclusão}

De maneira geral a temperatura constante de $25 \stackrel{\circ}{\circ}$ e os substratos areia, areia + Bioplant $^{\circledR}$ e areia + vermiculita, mostraram-se os mais indicados para a germinação e vigor de sementes de tomateiro.

\section{Agradecimentos}

À Coordenação de Aperfeiçoamento de Pessoal de Nível Superior (Capes), ao Conselho Nacional de Desenvolvimento Científico e Tecnológico (CNPq), à Fundação de Amparo à Pesquisa do Estado de Minas Gerais (Fapemig), pelo apoio financeiro, e à Universidade Estadual 
de Montes Claros (Unimontes), pelo apoio técnico para o desenvolvimento desta pesquisa.

\section{Referências}

ABUD, H.F.; ARAÚJO, E.F.; ARAÚJO, R.F.; ARAÚJO, A.V.; PINTO, C.M.F. Qualidade fisiológica de sementes das pimentas malagueta e biquinho durante a ontogênese. Pesquisa Agropecuária Brasileira, v.48, n.12, p.1546-1554, 2013. https://doi.org/10.1590/S0100-

$\underline{204 \times 2013001200003}$

ALVES, C.Z.; SILVA, J.B.; CÂNDIDO, A.C.S. Metodologia para a condução do teste de germinação em sementes de goiaba. Revista Ciência Agronômica, v.46, n.3, p.615-621, 2015. http://dx.doi.org/10.5935/1806-6690.20150045

ALVES, E.U.; ANDRADE, L.A.; BRUNO, R.L.A.; VIEIRA, R.M.; CARDOSO, E.A. Emergência e crescimento inicial de plântulas de Peltophorum dubium (Spreng.) Taubert sob diferentes substratos. Revista Ciência Agronômica, v.42, n.2, p.1-9, 2011. http://dx.doi.org/10.1590/S1806$\underline{66902011000200025}$

ARAGÃO, C.A.; MENEZES, L.P.; MAYARA, M.; FERREIRA, B.P.; FRANÇA, D.B. Qualidade de mudas de melão produzidas em diferentes substratos. Revista Caatinga, v.24, n.3, p.209214, 2011.

BIASI, L.A.; BILIA, D.A.C.; SÃO JOSÉ, A.R.; FORNASIERI, I.; MINAMI, K. Efeito de turfa e bagaço de cana sobre produção de mudas de tomate. Scientia Agrícola, v.52, n.2, p.239-243, $1995 . \quad$ http://dx.doi.org/10.1590/S010390161995000200006

BRASIL. Ministério da Agricultura, Pecuária e Abastecimento. Regras para análise de sementes. Secretaria de Defesa Agropecuária. Brasília: Mapa/ACS, 2009. 395p.

CARVALHO, N.M.; NAKAGAWA, J. Sementes: ciência, tecnologia e produção. 5. ed. Jaboticabal: FUNEP, 2012. 590p.

FERREIRA, S.M.R.; FREITAS, R.J.S.; LAZZARI, E.N. Padrão de identidade e qualidade do tomate (Lycopersicon esculentum Mill.) de mesa. Ciência Rural, v.34, n.1, p.329-335, 2004.
http://dx.doi.org/10.1590/S0103$\underline{84782004000100054}$

FIGLIOLA, M.B.; OLIVEIRA, E.C.; PIÑA-RODRIGUES, F.C.M. Análise de sementes. In: AGUIAR, I.B.; PIÑA-RODRIGUES, F.C.M.; FIGLIOLA, M.B. Sementes florestais tropicais. Brasília: Associação Brasileira de Tecnologia de Sementes, 1993. p.137-174.

FILGUEIRA, F.A.R. Novo manual de olericultura: Agrotecnologia moderna na produção e comercialização de hortaliças. 3. ed. Viçosa: UFV, 2013. $421 \mathrm{p}$.

GONZÁLEZ-RIVAS, B.; TIGABU, M.; CASTROMARÍN, G.; ODÉN, P.C. Seed germination and seedling establishment of neotropical dry forest species in response to temperature and light conditions. Journal of Forestry Research, v.20, n.2, p.99-104, 2009. https://doi.org/10.1007/s11676-009-0018-y

GUEDES, R.S.; ALVES, E.U.; GONÇALVES, E.P.; JÚNIOR, J.M.B.; VIANA, J.S.; COLARES, P.N.Q. Substratos e temperaturas para testes de germinação e vigor de sementes de Amburana cearensis (Allemão) A.C. Smith. Revista árvore, v.34, n.1, p.57-64, 2010. http://dx.doi.org/10.1590/S0100$\underline{67622010000100007}$

LIMA, C.R.; MAURO, P.V.; BRUNO, R.L.A.; FERRARI, C.S.; JÚNIOR, J.M.; BEZERRA, A.K.D. Temperaturas e substratos na germinação de sementes de Caesalpinia pyramidalis Tul. Revista Brasileira de Sementes, v.33, n.2, p.216-222, $2011 . \quad$ http://dx.doi.org/10.1590/S010131222011000200003

LONE, A.B.; SOUZA, G.R.B.; OLIVEIRA, K.S.; TAKAHASHI, L.A.S.; FARIA, R.T. Temperatura e substrato para germinação de sementes de florde-maio (Schlumbergera truncata (Haw.) Moran. Revista Ceres, v.57, n.3, p.367-371, 2010. http://dx.doi.org/10.1590/S0034$\underline{737 X 2010000300012}$

MAGUIRE, J.A. Speed of germination: aid in selection and evaluation for seedling enorgence and vigor. Crop Science, v.2, p.176-177, 1962.

MARCOS FILHO, J. Fisiologia de sementes de plantas cultivadas. Londrina: Abrates, 2015. 
https://doi.org/10.2135/cropsci1962.0011183X0 $\underline{00200020033 x}$

MEDEIROS, D.C.; FREITAS, K.C.S.; VERAS, F.S.; ANJOS, R.S.B.; BORGES, R.D.; CAVALCANTE NETO, J.G.; NUNES, G.H.S.; FERREIRA, H.A. Qualidade de mudas de alface em função de substratos com e sem biofertilizante. Horticultura Brasileira, v.26, n.2, p.186-189, 2008. http://dx.doi.org/10.1590/S0102$\underline{05362008000200011}$

NAKAGAWA, J. Testes de vigor baseados no desempenho das plântulas. In: KRZYZANOWSKI, F.C.; VIEIRA, R.D.; FRANÇA NETO, J.B. Vigor de sementes: conceitos e testes. Londrina: Associação Brasileira de Tecnologia de Sementes, 1999. p.1-24.

OLIVEIRA, L.M.; BRUNO, R.L.A.; SILVA, K.R.G.; SILVA, V.D.M.; FERARRI, C.S.; SILVA, G.Z. Germinação e vigor de sementes de Sapindus saponaria L. submetidas a tratamentos prégerminativos, temperaturas e substratos. Revista Ciência Rural, v.42, n.4, p.638-644, 2012. http://dx.doi.org/10.1590/S0103$\underline{84782012000400010}$

PACHECO, M.V.; MATTEI, V.L.; MATOS, V.P.; SENA, L.H.M. Germination and vigor of Dimorphandra mollis benth. seeds under different temperatures and substrates. Revista Árvore, v.34, n.2, p.205-213, 2010. http://dx.doi.org/10.1590/\$0100$\underline{67622010000200002}$

SANTOS, M.R.; SEDIYAMA, A.N.; SALGADO, L.T.; VIDIGAL, S.M.; REIGADO, F.R. Produção de mudas de pimentão em substratos à base de vermicomposto. Jornal Biosciências, v.26, n.4, p.572-578, 2010.

SOUZA, F.C.; MENGARDA, L.H.G.; SPADETO, C.; LOPES, J.C. Substratos e temperaturas na germinação de sementes de Gonçalo-alves (Astronium concinnum Schott). Revista Tropica: Ciências Agrárias e Biológicas, v.6, n.3, p.76-86, 2012.

YA-DAN, D.; HONG-XIA, C.; SHI-QUAN, L.; XIAOBO, G.; YU-XIN, C. Response of yield, quality, water and nitrogen use efficiency of tomato to different levels of water and nitrogen under drip irrigation in Northwestern China. Journal of
Integrative Agriculture, v.16, p.1153-1161, 2017. https://doi.org/10.1016/S2095-3119(16)61371-0 